\title{
Acute Inhalation Toxicology and Proposed Emergency Exposure Limits of Nitrogen Trifluoride ${ }^{1,2}$
}

\author{
E. H. Vernot, C. C. Haun, J. D. MacEwen and G. F. Egan ${ }^{3}$ \\ University of California, Overlook Branch, Dayton, Ohio 45431 and \\ Department of Industrial Toxicology, School of Public Health, \\ University of Michigan, Ann Arbor, Michigan 48104
}

Received March 22, 1971; accepted January 9, 1973

\begin{abstract}
Acute Inhalation Toxicology and Proposed Emergency Exposure Limits of Nitrogen Trifluoride. Vernot, E. H., Haun, C. C., MacEwen, J. D. ANd Egan, G. F. (1973). Toxicol. Appl. Pharmacol. 26, 1-13. Acute exposures of rats, mice, dogs and monkeys to nitrogen trifluoride have been carried out and median lethal concentrations were determined for rats and mice. Confirmative evidence was obtained that the immediate effects of acute exposure are caused by extensive methemoglobin formation and resulting anoxia. Dogs surviving exposure to $9600 \mathrm{ppm}$ for $60 \mathrm{~min}$ exhibit a Heinz body anemia with red blood cell count, hemoglobin and hematocrit decreasing $33 \%$ to minimum values by the end of the second week postexposure. Recovery of hematologic values to preexposure levels is attaincd in 40 days. In dogs, the anemia caused by a dose level of $120,000 \mathrm{ppm}-\mathrm{min}$ is severe enough to invalidate that dose as an emergency exposure limit (EEL). At 30,000 ppm-min, however, no detectable anemia occurs, and no other toxic effects are discernible. The results of experiments conducted at subacute levels justify recommending an upward revision of the EEL to $30,000 \mathrm{ppm}$-min from the proposed National Academy of Science, National Research Council value of 3000 ppm-min.
\end{abstract}

Nitrogen trifluoride $\left(\mathrm{NF}_{3}\right)$ is the least reactive of the fluorine containing rocket oxidizers which include, in addition to molecular fluorine itself, tetrafluorohydrazine $\left(\mathrm{N}_{2} \mathrm{~F}_{4}\right)$, oxygen difluoride $\left(\mathrm{OF}_{2}\right)$ and the interhalogen compounds such as bromine pentafluoride $\left(\mathrm{BrF}_{5}\right)$, chlorine pentafluoride $\left(\mathrm{CIF}_{5}\right)$ and chlorine trifluoride $\left(\mathrm{CIF}_{3}\right)$. In spite of the fact that no reaction between inorganic aqueous systems and $\mathrm{NF}_{3}$ takes place except under severe conditions (Hurst and Khayat, 1966), Dost et al. (1970) have shown that $\mathrm{NF}_{3}$ inhaled by rats reacts rapidly with hemoglobin to form methemoglobin. Evidence has also been presented by previous investigators (Ruff, 1931; Torkelson

${ }^{1}$ The experiments reported herein were conducted according to the "Guide for Laboratory Animal Facilities and Care" (1965), prepared by the Committee on the Guide for Laboratory Animal Resources, National Academy of Sciences/National Research Council; the regulations and standards prepared by the Department of Agriculture ; and Public Law 89-544, "Laboratory Animal Welfare Act," August 24, 1967.

2 Presented at the Ninth Annual Meeting of the Society of Toxicology, Atlanta, Georgia, March 15-19, 1970.

${ }^{3}$ Department of Industrial Toxicology, School of Public Health, University of Michigan, Ann Arbor, Michigan 48104. 
et. al., 1962; Dost et al., 1970) that the acute inhalation toxicity of nitrogen trifluoride $\left(\mathrm{NF}_{3}\right)$ is due to massive formation of methemoglobin, with death ensuing from the resulting anoxia. These studies were performed with rats only and did not quantitate the acute inhalation toxicity of $\mathrm{NF}_{3}$ by determination of median lethal concentration (LC50) values. The investigations reported here were, therefore, undertaken to evaluate the $\mathrm{NF}_{3} \mathrm{LC50}$ at 15, 30 and $60 \mathrm{~min}$ in rats and mice and lethal concentrations to dogs and monkeys. Additionally, experiments were conducted to determine what short-term exposure levels of $\mathrm{NF}_{3}$ would have no significant effects on all species tested. The latter series of tests was carried out to aid in setting up realistic emergency exposure limits. Present EEL values for $\mathrm{NF}_{3}$ proposed by the Committee on Toxicology, Advisory Center on Toxicology, National Academy of Science, National Research Council (NAS/NRC) are $100 \mathrm{ppm}$ for $30 \mathrm{~min}$ and $50 \mathrm{ppm}$ for $60 \mathrm{~min}$, corresponding to a dose level of $3000 \mathrm{ppm}-\mathrm{min}$.

\section{METHODS}

Rodent exposures. Male Sprague-Dawley strain rats and ICR mice were exposed in groups of 10 in a 30-liter bell-jar chamber. The rats were allowed to run free in the chamber on a flat surface of wire mesh. The $\mathrm{NF}_{3}$ was introduced into the air stream prior to entry into a duplicate chamber which was used to establish contaminant concentrations. Animals were loaded into the test chamber which was isolated from the contaminant introduction system by a 2 -way valve. Air flow was fixed at $30 \mathrm{liters} / \mathrm{min}$ and was adjusted to give the desired concentration in the duplicate chamber determined by analysis. At this time, the valve was switched and the air stream containing the contaminant was directed into the test chamber. Wire mesh separated the animals from the point of atmosphere introduction. Exposure of animals was timed from the switching of contaminant into the chamber. The contaminant introduction into the air stream was closed off after 15,30 or $60 \mathrm{~min}$, and air was allowed to pass through the chamber for 10 min more; then the chamber was opened and the animals removed. Application of Silver's Equation (Silver, 1946) demonstrated that $95 \%$ of the equilibrium concentration of $\mathrm{NF}_{3}$ was achieved in $3 \mathrm{~min}$. The decay of the concentration after the contaminant was turned off matched the rate of increase at the beginning of exposure, so that the same concentration $\times$ time (CT) dose level was delivered to the animals as though the concentration had been immediately established and cut off.

Animals surviving exposure were held up to 2 weeks to include delayed deaths in the mortality compilation. LC50 calculations for rodents were made by a computerized version of the probit method of Finney (1964).

Monkey and dog exposures. Male and female beagle dogs and rhesus monkeys were exposed in groups of 3 in a modified Rochester Chamber described by Haun et al. (1969). Concentration was established in the test chamber using a 50 cubic feet per min (cfm) air flow rate and verified by analysis prior to introduction of the animals. The chamber door was then opened, and the animals were introduced as quickly as possible, a procedure that never took more than $1 \mathrm{~min}$ to accomplish. Analysis demonstrated that the concentration immediately after closure of the chamber door was always within $10 \%$ of the desired value.

In selected acute experiments, blood was drawn from the survivors immediately after exposure and every hour thereafter for measurement of turbidity, oxyhemoglobin 
and methemoglobin using procedures detailed in the Appendix. Sampling was continued until methemoglobin dropped to preexposure values. These experiments, however, were not used to estimate the lethality of a particular concentration. As with rodents, surviving monkeys and dogs were held for up to 2 weeks after exposure, but no deaths occurred more than $2 \mathrm{hr}$ postexposure. Gross pathology examinations were performed on animals dying of acute exposure and on the survivors when sacrificed at varying intervals after exposure. Tissues were also taken for histopathologic examinations.

A 60-min exposure of 18 dogs to $9600 \mathrm{ppm}$ was carried out, and survivors held for 6 weeks during which hematologic parameters were determined at intervals of 3-5 days on blood drawn from the jugular vein. Hematocrit was measured using microhematocrit tubes, and red blood cells were counted by a commercial instrument (Coulter Electronics, Inc.). Reticulocytes were counted in 1000 red cells after staining slide smears with brilliant cresyl blue. The percentage of red cells containing Heinz bodies was also estimated after staining with this dye by examination of 100 red cells. Hemoglobin and turbidity were measured by the method given in the Appendix.

TABLE 1

MORTALITY in RATS EXPOSED TO $\mathrm{NF}_{3}$ TOR 15, 30 AND

60 MinUtes

\begin{tabular}{|c|c|c|}
\hline \multicolumn{2}{|r|}{ Concentration, ppm } & \multirow[b]{2}{*}{ Mortality } \\
\hline $\operatorname{Mean}^{a}$ & Range & \\
\hline \multicolumn{3}{|c|}{15 Minutes } \\
\hline 19,316 & $17,500-20,200$ & $0 / 10$ \\
\hline 21,430 & $18,500-23,500$ & $0 / 10$ \\
\hline 25,200 & $23,500-25,900$ & $3 / 10$ \\
\hline 28,257 & $27,000-28,800$ & $7 / 10$ \\
\hline 28,930 & $26,500-30,000$ & $8 / 10$ \\
\hline 30,714 & $28,600-31,200$ & $10 / 10$ \\
\hline \multicolumn{3}{|c|}{ LC50: $26,700 \mathrm{ppm}(25,640-27,610)^{b}$} \\
\hline \multicolumn{3}{|c|}{30 Minutes } \\
\hline 8,204 & $8,036-8,282$ & $0 / 10$ \\
\hline 10,250 & $10,004-10,436$ & $3 / 10$ \\
\hline 11,257 & $11,070-11,316$ & $1 / 10$ \\
\hline 12,281 & $12,218-13,300$ & $7 / 10$ \\
\hline 13,226 & $13,202-13,407$ & $9 / 10$ \\
\hline \multicolumn{3}{|c|}{ LC50: $11,700 \mathrm{ppm}(11,080-12,330)^{b}$} \\
\hline \multicolumn{3}{|c|}{60 Minutes } \\
\hline 4,118 & $4,018-4,428$ & $0 / 10$ \\
\hline 5,117 & $5,002-5,298$ & $1 / 10$ \\
\hline 6,121 & $5,986-6,232$ & $4 / 10$ \\
\hline 7,190 & $7,134-7,257$ & $5 / 10$ \\
\hline 8,204 & $8,036-8,282$ & $9 / 10$ \\
\hline \multicolumn{3}{|c|}{ LC50: $6,700 \mathrm{ppm}(6,130-7,320)^{b}$} \\
\hline
\end{tabular}

${ }^{a}$ Values are means of concentrations measured every 2 min.

${ }^{b}$ Numbers in parentheses are $95 \%$ confidence limits. 
Emergency exposure limit (EEL) studies. Experiments were conducted for 15, 30 and $60 \mathrm{~min}$ at dose levels of 120,000 and $30,000 \mathrm{ppm}-\mathrm{min}$. For each concentration tested during EEL experiments, 6 dogs, 6 monkeys, 30 mice and 30 rats were used, with identical numbers of control animals. Separate exposures were conducted in the Rochester Chambers for the dogs, uncaged, the monkeys, caged singly, and the rodents, 10 to a cage. Animals exposed to the EEL test concentrations of $\mathrm{NF}_{3}$ were held for 4 weeks postexposure. During this period, body weights were obtained weekly and hematologic parameters were measured twice weekly. After 4 weeks, the animals were killed for pathologic examination of all species and weight measurement of rat organs.

Chamber contaminant analysis. A gas chromatographic procedure was developed for the analysis of $\mathrm{NF}_{3}$ chamber concentrations utilizing a 6-foot silica gel column thermostatically controlled to $40^{\circ} \mathrm{C}$, with a helium carrier gas flow of $100 \mathrm{cc} / \mathrm{min}$ and thermal conductivity detection. Chamber atmosphere, sampled from the vicinity of the experimental animals, was pumped through a manual gas sampling valve for introduction into the gas chromatograph. For standardization, samples were prepared by injection of pure $\mathrm{NF}_{3}$ into Mylar ${ }^{\circledR}$ bags which had been filled with known volumes

TABLE 2

MORTALITY IN MiCe EXPOSED to $\mathrm{NF}_{3}$ FOR 15, 30 AND 60 Minutes

\begin{tabular}{rcr}
\hline \multicolumn{2}{c}{ Concentration, ppm } \\
\cline { 1 - 2 } Mean $^{a}$ & Range & Mortality \\
\hline \multicolumn{3}{c}{15 Minutes } \\
17,515 & $15,800-18,000$ & $3 / 10$ \\
20,130 & $17,800-20,900$ & $6 / 10$ \\
22,030 & $18,200-23,500$ & $7 / 10$ \\
23,570 & $19,300-24,300$ & $9 / 10$ \\
& LC50: 19,300 ppm $(17,910-20,910)^{b}$ \\
\hline \multicolumn{3}{c}{30 Minutes } \\
10,222 & $8,118-8,323$ \\
10,906 & $9,840-10,496$ & $0 / 10$ \\
11,234 & $10,742-11,070$ & $1 / 10$ \\
12,327 & $11,152-11,275$ & $1 / 10$ \\
16,293 & $12,136-12,628$ & $5 / 10$ \\
& $16,154-16,400$ & $6 / 10$ \\
& LC50: 12,300 ppm $(11,460-13,160)^{b}$ & $9 / 10$ \\
4,112 & 60 Minutes \\
6,469 & $3,854-4,264$ \\
7,150 & $6,297-6,560$ \\
8,200 & $6,888-7,544$ & $0 / 10$ \\
12,218 & $8,150-8,250$ & $3 / 10$ \\
& $12,136-12,300$ & $4 / 10$ \\
& LC50: 7,500 ppm $(6,800-8,280)^{b}$ & $6 / 10$ \\
\hline
\end{tabular}

${ }^{a}$ Values are means of concentrations measured every 2 min.

${ }^{b}$ Numbers in parentheses are $95 \%$ confidence limits. 
of air measured by a wet test gas meter. Before entering the bag, the air passed through a desiccant tube to remove water. Analyses of replicate bags showed the $95 \%$ confidence limits of the method to be $\pm 5 \%$ of any concentration generated for this study. Determinations were performed every $2 \mathrm{~min}$ which was satisfactory for the monitoring of 15 min or longer exposures.

\section{Acute Exposures}

\section{RESULTS}

Because of the ready availability of rats and mice, they were selected for determination of LC50 values which had a measurable degree of statistical precision. Smaller groups of monkeys and dogs were subsequently exposed to determine whether lethal concentrations for these species differed from rodents to any great degree. The mortality data for rats and mice are listed in Tables 1 and 2, respectively, along with the LC50 values and $95 \%$ confidence limits. The comparable information for dogs and monkeys is given in Table 3. The approximate LC50's shown in Table 3 have not been assigned confidence limits since the numbers used in the large animal experiments were too small to yield precise values of LC50's. They are included, however, for the purpose of comparison with rodent data, and indicate that dogs may be more resistant to the lethal effects of $\mathrm{NF}_{3}$ at 15 and 30 min than the other three species.

TABLE 3

Mortality in Dogs and Monkeys EXPOSEd to $\mathrm{NF}_{3}$ FOR 15,30 and 60 MinUTES

\begin{tabular}{|c|c|c|c|c|c|}
\hline \multicolumn{3}{|c|}{ Dogs } & \multicolumn{3}{|c|}{ Monkeys } \\
\hline \multicolumn{2}{|c|}{ Concentration, ppm } & \multirow[b]{2}{*}{ Mortality } & \multicolumn{2}{|c|}{ Concentration, ppm } & \multirow[b]{2}{*}{ Mortality } \\
\hline $\operatorname{Mean}^{a}$ & Range & & Mean $^{a}$ & Range & \\
\hline \multicolumn{6}{|c|}{15 Minutes } \\
\hline 31,816 & $22,468-45,100$ & $0 / 3$ & 21,250 & $20,400-22,000$ & $0 / 3$ \\
\hline 37,600 & $35,900-39,200$ & $2 / 5$ & 23,490 & $21,812-27,880$ & $1 / 2$ \\
\hline 41,410 & $23,780-53,546$ & $2 / 3$ & 25,026 & $23,370-32,636$ & $1 / 2$ \\
\hline 43,460 & $37,228-50,184$ & $3 / 3$ & 27,150 & $21,500-30,100$ & $3 / 3$ \\
\hline \multicolumn{3}{|c|}{$\mathrm{ALC} 50^{b}: 38,000 \mathrm{ppm}$} & \multicolumn{3}{|c|}{$\operatorname{ALC} 50^{b}: 24,000 \mathrm{ppm}$} \\
\hline \multicolumn{6}{|c|}{30 Minutes } \\
\hline 19,434 & $14,760-21,484$ & $0 / 3$ & 13,038 & $7,790-18,040$ & $0 / 3$ \\
\hline 20,779 & $16,810-23,158$ & $2 / 3$ & & & \\
\hline 24,026 & $21,484-25,092$ & $3 / 3$ & 15,170 & $14,432-15,580$ & $3 / 3$ \\
\hline \multicolumn{3}{|c|}{$\mathrm{ALC}^{5} 0^{b}: 20,400 \mathrm{ppm}$} & \multicolumn{3}{|c|}{ 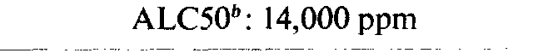 } \\
\hline \multicolumn{6}{|c|}{60 Minutes } \\
\hline \multirow[t]{2}{*}{8,550} & \multirow[t]{2}{*}{$7,790-8,900$} & \multirow[t]{2}{*}{$0 / 2$} & 8,519 & $8,446-8,815$ & $0 / 2$ \\
\hline & & & 9,390 & $7,300-11,100$ & $1 / 3$ \\
\hline 9,947 & $9,020-10,496$ & $2 / 3$ & 9,947 & $9,020-10,496$ & $1 / 3$ \\
\hline \multirow{2}{*}{11,450} & $10,824-11,808$ & $2 / 2$ & 11,273 & $9,922-11,808$ & $3 / 3$ \\
\hline & \multicolumn{2}{|l|}{$\mathrm{ALC}^{2} 0^{b}: 9,600 \mathrm{ppm}$} & \multicolumn{3}{|c|}{ ALC50 $0^{b}: 10,000 \mathrm{ppm}$} \\
\hline
\end{tabular}

${ }^{a}$ Values are means of concentrations measured every 2 min.

${ }^{b}$ Approximate LC50. 
The lines in Fig. 1 are least squares best fits to the LC50 rodent data plotted versus the reciprocal of the exposure time. If the classical relationship of $\mathrm{LC} 50 \times T=K$ were applicable, one would expect straight line plots extending through the origin. In the case of rats, the classical relationship is demonstrated. However, the line for mice does not pass through the origin but shows an intercept at $3900 \mathrm{ppm}$. A consequence of this is that the relative toxicity of $\mathrm{NF}_{3}$ to rats and mice should undergo inversion at about 40 min exposure $\left(1 / T=25 \times 10^{-3}\right.$ reciprocal $\left.\mathrm{min}\right)$. The difference in LC50's demonstrates that rats are more resistant than mice at $15 \mathrm{~min}$. It is, however, difficult to see any difference between the rat and mouse values at $60 \mathrm{~min}$ because of the overlap in confidence limits. Therefore, in an effort to obtain supporting evidence of the inversion,

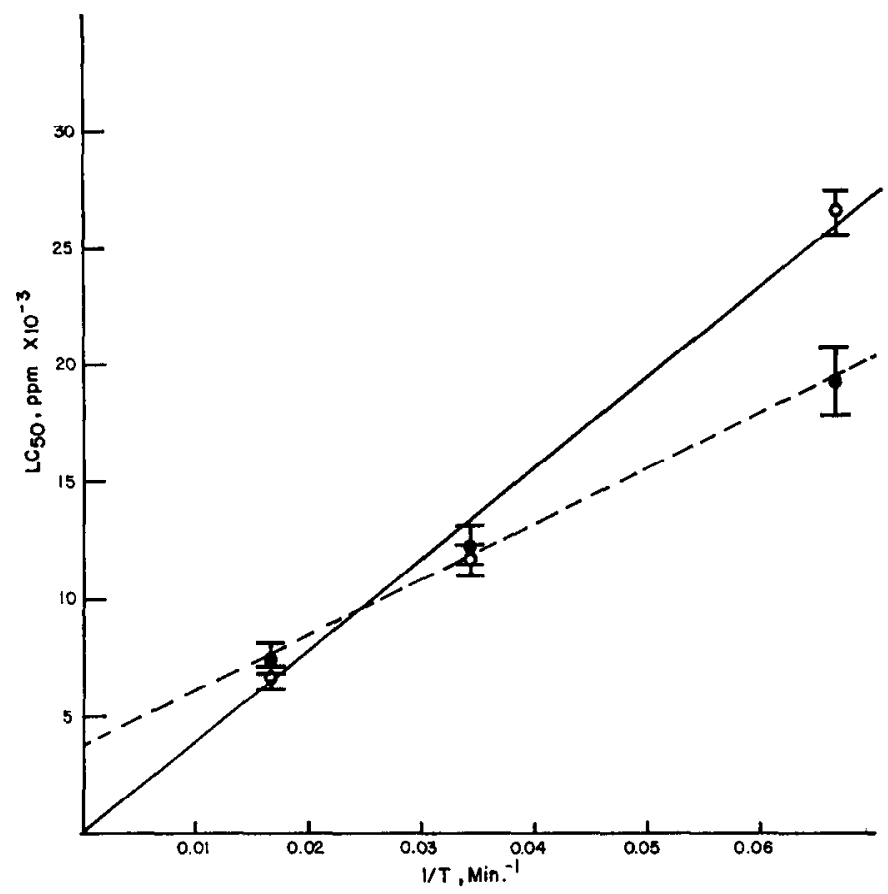

Fig. 1. Regression lines, LC50 versus reciprocal of time for rats $(\mathrm{O}-\mathrm{O})$ and mice ( Data points are LC50 values at 15, 30 and 60 min and vertical bars represent $95 \%$ confidence limits.

an additional experiment was performed in which 10 rats and 10 mice were exposed to $4500 \mathrm{ppm}$ of $\mathrm{NF}_{3}$ for $120 \mathrm{~min}$. The mice experienced $20 \%$ mortality and the rats $90 \%$ from this exposure, a further indication that the inversion of toxic effect does occur.

Approximately $90 \%$ of the rat deaths occurred within the first 60 min postexposure, with most observed in the first $10 \mathrm{~min}$. There were no deaths noted after $24 \mathrm{hr}$. Although $50 \%$ of the mice succumbed during exposure, there were more delayed deaths than in rats. Many survived for several hr, a few for 1 day, and 1 animal for 3 days. Those mice dying after 1 day showed extensive pneumonia on pathologic examination. The dogs and monkeys that did not recover almost always died within $1 \mathrm{hr}$ after exposure.

Some eye irritation was noted in all species during exposure. Except for this, clinical signs appeared to result from anoxia due to methemoglobin formation and included rapid breathing, gasping and cyanosis in all animals and emesis in dogs and monkeys. 
Survival in monkeys and dogs acutely exposed to $\mathrm{NF}_{3}$ was dependent upon the amount of methemoglobin produced or, conversely, on the amount of oxyhemoglobin remaining in the blood as measured immediately after exposure. Conversion of oxyhemoglobin to methemoglobin, such that less than $4 \mathrm{~g} / 100 \mathrm{ml}$ oxyhemoglobin remained, invariably resulted in death of the animal. Hourly measurement of methemoglobin concentrations starting immediately after exposure showed a rapid linear decrease with a corresponding increase in oxyhemoglobin until preexposure values

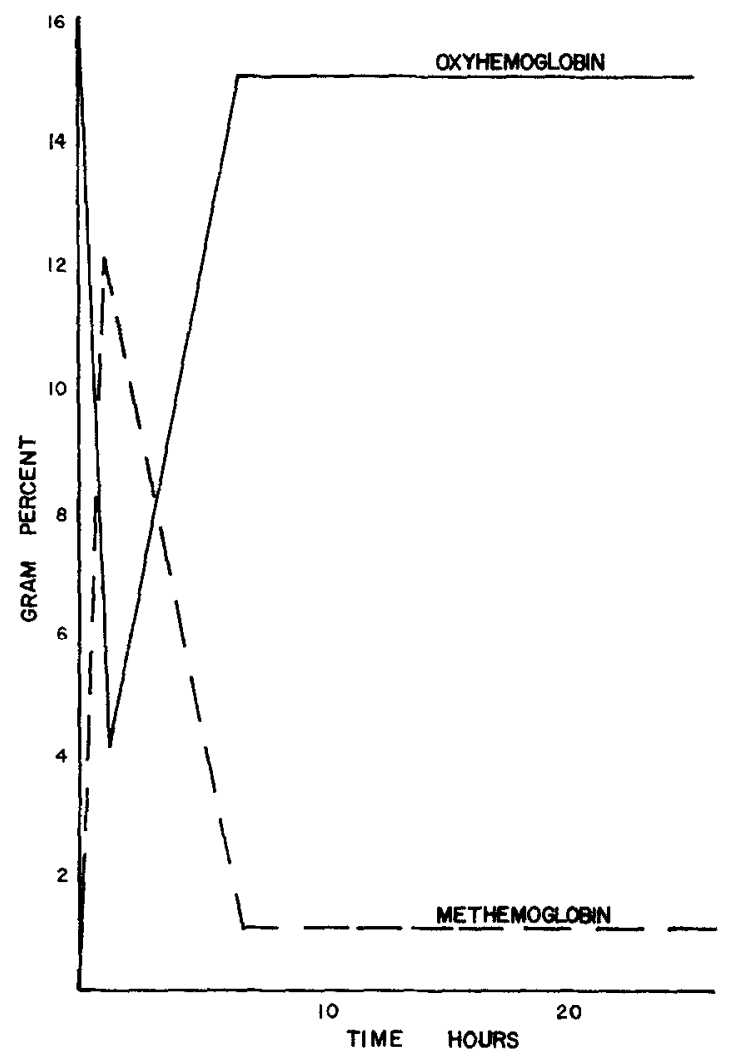

FIG. 2. Effect of acute $\mathrm{NF}_{3}$ exposure on dog hemoglobin. Blood of 10 dogs surviving acute exposure was sampled before the exposure, immediately postexposure, and hourly for $7 \mathrm{hr}$, then every other hour in the interval of $20-30 \mathrm{hr}$ post-exposure. Plot is curve connecting the medians of these values.

of methemoglobin were attained some $5-10 \mathrm{hr}$ postexposure. Fig. 2 is a diagram of the course of methemoglobin conversion to oxyhemoglobin which was seen in all dogs surviving acute exposures. The pattern of methemoglobin development and postexposure disappearance was identical in monkeys.

Although methemoglobin returned to baseline levels, oxyhemoglobin concentrations after disappearance of methemoglobin were about $1 \mathrm{~g} / 100 \mathrm{ml}$ lower than preexposure values. Concurrent with this observation, the turbidity of the diluted blood was higher after exposure. Since the production of Heinz bodies is a common result of methemoglobin formation by such materials as phenylhydrazine(Jandlet al., 1960), the possibility 
existed that the postexposure turbidity was caused by denaturation of the hemoglobin and subsequent Heinz body formation. Staining the blood sampled with cresyl blue, a standard vital stain for Heinz body detection, revealed the presence of numerous Heinz bodies in the red cells. Hemolyzed blood used for spectrophotometric analysis was centrifuged, and staining the residue with cresyl blue disclosed that it consisted mainly of quasicrystalline granules identical to those seen previously in the red cells. This was strong evidence that the turbidity in the blood of exposed animals was, in fact, due to the presence of Heinz bodies.

Gross and histopathologic findings in those animals that died during or after exposure were consistent with a diagnosis of anoxia and massive methemoglobin formation.

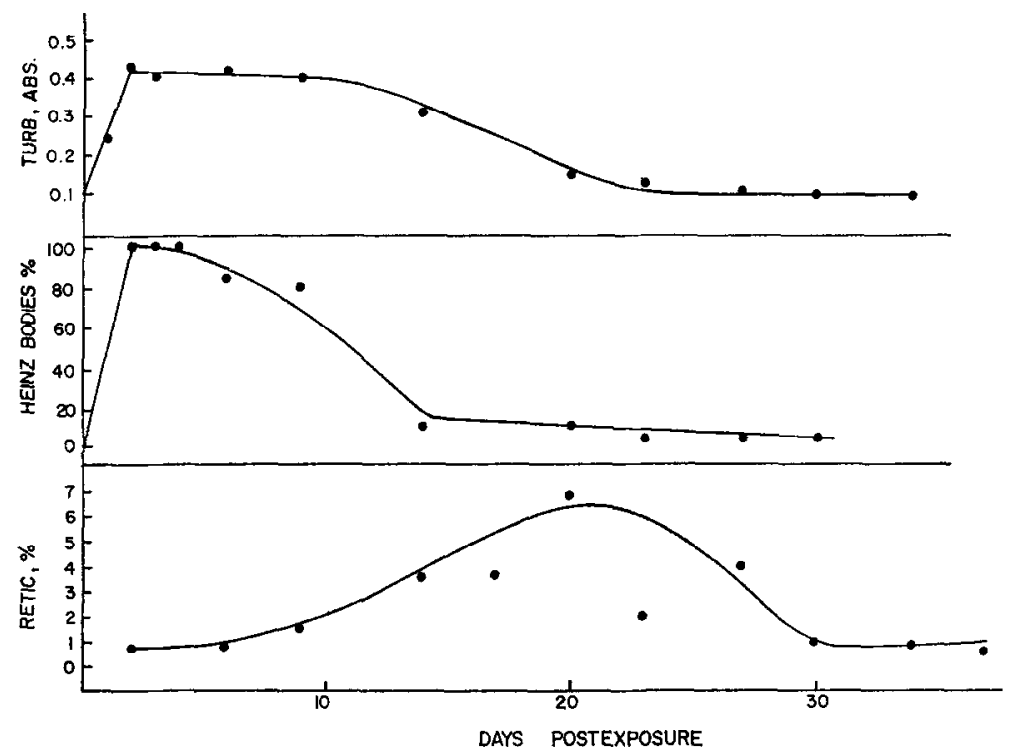

Fig. 3. Effect of exposure to the 60-min LC50 ( $9600 \mathrm{ppm})$ on 14 surviving dogs. Values are means of 14 measurements. Turbidity is plotted in absorbance units at $720 \mathrm{~nm}$ and Heinz bodies in percent of cells containing bodies. Reticulocytes are counted in 1000 red cells.

These findings included lung congestion, edema, and focal hemorrhage. Additionally, all organs of the viscera were congested, showing a pale to dark brown color, depending on the degree of methemoglobin formation. In all animals that survived acute exposures and were held 2 weeks or longer, no gross or histopathologic effects of exposure were noted.

In order to follow more precisely the course of hematologic changes caused by exposure to $\mathrm{NF}_{3}$, a group of 18 dogs was exposed to $9600 \mathrm{ppm}$, the LC50 concentration for $60 \mathrm{~min}$, and the survivors were held for 40 days. Figures 3 and 4 depict the hematologic changes with time resulting from acute exposure to $\mathrm{NF}_{3}$. The close correspondence between turbidity and Heinz bodies is readily seen in Fig. 3. Difference between the plots may be explained by the fact that the Heinz body measurement consisted of counting all red blood cells containing any Heinz bodies. Multiple inclusion bodies in individual cells, although seen, were not recorded. Heinz bodies attained a maximum some 2 days after exposure, remained fairly constant at a plateau for about 2 weeks, and 
decreased to zero after 3 weeks. Reticulocyte determinations gave scattered results, but appeared to peak at about $6 \%$ after 3 weeks, returning to normal after 30 days.

As illustrated in Fig. 4, red blood cells, hemoglobin and hematocrit all showed approximately the same $33 \%$ decrease at about 2 weeks postexposure. The hematologic values then increased slowly, reattaining normal values at the end of the holding period. The clinical picture presented is one of a typical Heinz body anemia caused by intoxication with chemicals such as aniline, nitrobenzene and phenylhydrazine (Necheles and Allen, 1969; von Oettingen et al., 1947; Selwyn, 1955).

\section{Emergency Exposure Limit Studies}

As noted previously, the NAS/NRC has set a tentative $\mathrm{NF}_{3}$ EEL dose of 3000 ppm$\min$ for 30 and $60 \mathrm{~min}$. Since our work had indicated that the acute effects of $\mathrm{NF}_{3}$ were

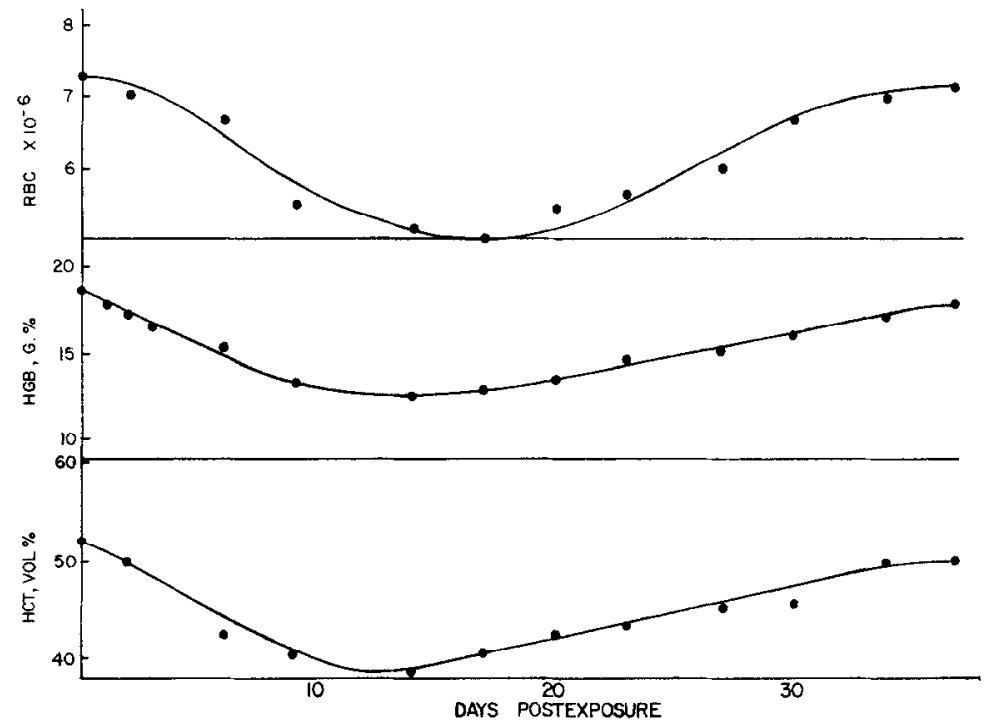

FIG. 4. Development of ancmia after cxposure to the $60-\mathrm{min} L C 50(9600 \mathrm{ppm})$ in 14 surviving dogs. Values are the mean of 14 measurements. HCT, hematocrit; HGB, hemoglobin; RBC, red blood cell count.

caused by anoxia due to methemoglobinemia and that the anemia following acute exposure was reversible, a number of experiments were performed at subacute levels to determine whether the NAS/NRC recommendation could be revised upward.

The acute effects of carbon monoxide $(\mathrm{CO})$, like those of $\mathrm{NF}_{3}$, result from anoxia and, since the EEL for $\mathrm{CO}$ is based upon a concentration which causes conversion of $15 \%$ of the oxyhemoglobin to carboxyhemoglobin, an $\mathrm{NF}_{3}$ dose causing conversion of $15 \%$ of the hemoglobin to methemoglobin was thought to represent an EEL value suitable for testing. Initial experiments indicated that a $120,000 \mathrm{ppm}-\mathrm{min}$ dose level of $\mathrm{NF}_{3}$ would cause $15 \%$ conversion of hemoglobin to methemoglobin. Therefore, dogs, monkeys, rats and mice were exposed to this dose level for 15, 30 and $60 \mathrm{~min}$. As Table 4 shows, the aim of $15 \%$ conversion was fairly well achieved in all the exposures. No adverse signs were noted during exposure, and no effects were seen on body weight gain 
TABLE 4

Methemoglobin Produced by NF 3 , Aproximate 120,000 PPM-Minute dose ${ }^{a}$

\begin{tabular}{cccc}
\hline \multirow{2}{*}{$\begin{array}{c}\text { Time, } \\
(\mathrm{min})\end{array}$} & $\begin{array}{c}\text { Concentration } \\
(\mathrm{ppm})\end{array}$ & Dogs & Monkeys \\
\cline { 3 - 4 } & & $19.2 \pm 1.6$ & $16.5 \pm 1.0$ \\
15 & 7000 & $10.3 \pm 1.0$ & $15.0 \pm 0.5$ \\
30 & 3500 & $15.2+1.8$ & $10.3 \pm 2.1$ \\
60 & 2000 & &
\end{tabular}

${ }^{a}$ Six animals of each species tested per dose.

during the 28-day postexposure holding period, or on rat organ-to-body weight ratios at necropsy. Gross histopathologic examination revealed no differences from unexposed animals.

Hematologic parameters of the dogs and monkeys were followed during the 28 days postexposure, with no observed significant change from controls on the part of monkeys. The dogs, however, demonstrated decreases in hematocrit, hemoglobin and red blood cell count, with minimum values being reached at time periods comparable to those after acute exposure. Table 5 shows that the average decrease in these parameters was $16 \%$ compared with $33 \%$ for the lethality studies. Thus, even though the tested dose was only $20 \%$ of the LC50 dose, the decreases in hematocrit, hemoglobin, and red blood cell count for the dog averaged $50 \%$ of the LC50 values. These effects were important enough to remove from consideration the use of $120,000 \mathrm{ppm}-\mathrm{min} \mathrm{NF}_{3}$ as an EEL because individuals with various types of anemia might be adversely affected by such decreases.

TABLE 5

EfFect of $\mathrm{NF}_{3}$ Dose on Hematology Values in Dogs

\begin{tabular}{ccccc}
\hline & \multicolumn{2}{c}{$\begin{array}{c}\text { LC50 dose } \\
\text { 600,000 ppm-min }\end{array}$} & \multicolumn{2}{c}{$\begin{array}{c}\text { Expected EEL dose } \\
120,000 \text { ppm-min }\end{array}$} \\
\cline { 2 - 5 } Parameter $^{a}$ & $\%$ Decrease & Days to minimum & $\%$ Decrease & Days tominimum \\
\hline HCT & 35 & $9-17$ & 15 & $7-10$ \\
HGB & 33 & $9-14$ & 18 & 10 \\
RBC & 30 & $14-20$ & 16 & $10-14$ \\
\hline
\end{tabular}

${ }^{a}$ HCT, hematocrit; HGB, hemoglobin; RBC, red blood cells.

Since it appeared likely that the amount of methemoglobin found immediately postexposure was a good indicator of the magnitude of the ensuing anemia, a study was instituted to determine the maximum $\mathrm{NF}_{3}$ dose level which would produce no measurable methemoglobin in dogs within the precision of the technique used. Dogs were exposed to various concentrations for $60 \mathrm{~min}$, immediately after which the methemoglobin content of the blood was measured. Table 6 shows that an approximate 30,000 ppm-min dose level produced $2.2 \%$ conversion of hemoglobin to methemoglobin. Since this is a zero result within the precision of the technique, it was concluded that this dose of $\mathrm{NF}_{3}$ had no effect on the blood. 
TABLE 6

\begin{tabular}{cccc} 
Methemoglobin & Produced in Dogs by Various Doses of $\mathrm{NF}_{3}{ }^{a}$ \\
\hline $\begin{array}{c}\text { Concentration } \\
(\mathrm{ppm})\end{array}$ & $\begin{array}{c}\text { Dose } \\
\text { (ppm-min) }\end{array}$ & $\begin{array}{c}\text { Methemoglobin }(\%) \\
\text { Individual values }\end{array}$ & Mean \\
\hline $\mathbf{1 , 0 7 5}$ & $\mathbf{6 5 , 0 0 0}$ & $6.6,11.3,11.2$ & 9.7 \\
510 & 31,000 & $3.1,0.0,3.3$ & 2.2 \\
290 & 17,000 & $0.0,0.0,0.0$ & 0.0 \\
\hline
\end{tabular}

${ }^{a}$ All exposures were 60 min long. Three dogs were exposed at each level.

The EEL experiments previously carried out using a $120,000 \mathrm{ppm}-\mathrm{min}$ dose level were repeated for all species, using the $30,000 \mathrm{ppm}$-min dose level. Again, as expected no changes in body weight gain rate were noted during the 28-day postexposure period, or in rat organ-to-body weight ratio at necropsy. Gross and histopathologic examinations did not reveal any changes. In dogs, hematology values showed no decrease when compared to controls during the postexposure holding period. All the measurements made indicated that exposure to $30,000 \mathrm{ppm}-\mathrm{min}$ at 15,30 and $60 \mathrm{~min}$ had no detectable effect on any of the species tested.

\section{DISCUSSION}

Torkelson et al. (1962) exposed rats to $\mathrm{NF}_{3}$ for $30 \mathrm{~min}$ and $1 \mathrm{hr}$. Their data indicated that deaths occur after exposures to between 10,000 and $20,000 \mathrm{ppm}$ for $30 \mathrm{~min}$ and between 5000 and 10,000 ppm for $1 \mathrm{hr}$. These data compare well with our LC50 values for this species: $11,700 \mathrm{ppm}$ for $30 \mathrm{~min}$ and $6700 \mathrm{ppm}$ for $1 \mathrm{hr}$. Dost et al. (1970) found 1-hr exposures of rats to $10,000 \mathrm{ppm} \mathrm{NF}_{3}$ to be lethal to $87 \%$ of the animals tested. Essentially, therefore, our experiments have shown the same degree of $\mathrm{NF}_{3}$ toxicity to rats as have previous investigations. These earlier investigations also demonstrated that profound methemoglobinemia occurs in rats exposed to lethal concentrations of $\mathrm{NF}_{3}$ vapor. In our study, examination of dogs and monkeys exposed to high concentrations of $\mathrm{NF}_{3}$ demonstrated that the intensity of methemoglobinemia or, conversely, the amount of oxyhemoglobin remaining in the blood of animals surviving immediately postexposure determined whether the animals would recover or die. This fact, coupled with the toxic signs during exposure and the pathologic findings, indicates that the lethal effects of $\mathrm{NF}_{3}$ by the inhalation route are due to anoxia caused by extensive methemoglobin formation.

Horecker (1945) was the first investigator to report that the turbidity of hemolyzed blood from individuals exposed to trinitrotoluene was due to the presence of Heinz. bodies. He also noted that methemoglobin levels were slightly but significantly elevated in these subjects. Studies using experimental animals have shown the production of Heinz body anemias by many other chemicals (von Oettingen et al., 1947; Spicer. 1949; Sinha and Slight, 1968). The development of the anemia is remarkably consistent in each case described: rapid production of methemoglobin and slower increase of Heinz bodies, reaching a maximum a day or two after initial intoxication. A gradual decrease in total hemoglobin occurs shortly after exposure and reaches a minimum in 5 days to 2 weeks depending on the species used, exposure conditions and particular chemical tested. The progression of effects of $\mathrm{NF}_{3}$ exposure noted in this study followed this pattern very closely. 
There has been some uncertainty about the production of sulfhemoglobin (Jandl, 1960) as a result of exposure to Heinz body inducing agents and about the persistence of methemoglobin after termination of exposure (von Oettingen et al., 1947). Dost et al. (1970) reported an increase rather than a decrease of total hemoglobin in rats after acute intoxication with $\mathrm{NF}_{3}$. It is our belief that inferences concerning the presence of sulfhemoglobin, postexposure persistence of methemoglobin, and increased total hemoglobin after acute exposure to chemicals producing Heinz body anemia may have all been drawn from spectrophotometric measurement of absorbance in solutions made turbid by the presence of Heinz bodies.

In our experiments, the absorbances due to Heinz body turbidity at $630 \mathrm{~nm}$ and $578 \mathrm{~nm}$ were, respectively, 1.2 and 1.3 times the absorbance at $720 \mathrm{~nm}$. Therefore, the error due to turbidity, if it is not removed or corrected, becomes greater with decreasing wavelength and there will be absorbance increases at wavelengths when the following pigments are measured: methemoglobin- $-630 \mathrm{~nm}$, sulfhemoglobin-618 nm, and cyanmethemoglobin- $540 \mathrm{~nm}$. The practical result of an analysis for these blood pigments when undetected Heinz body turbidity is present will be that methemoglobin and sulfhemoglobin may be inferred to be present when they are not, or that the measured concentrations of all three will be higher than the true concentrations. Investigations of the effects of $\mathrm{NF}_{3}$ and monomethylhydrazine (which also causes methemoglobinemia and Heinz body anemia) in this laboratory have shown that, after correction for turbidity, no sulf hemoglobin is formed, methemoglobin returns to baseline levels 5 to $10 \mathrm{hrs}$ after termination of exposure, and total hemoglobin invariably decreases after exposure to those agents.

Although the dog was the most resistant species tested to the lethal effects of $\mathrm{NF}_{3}$, dog blood exhibited much more severe decreases in hematologic parameters after exposure to this material. For that reason, dogs are very sensitive test animals for determining $\mathrm{NF}_{3}$ emergency exposure limits, and the no-effect level found in this study probably contains an intrinsic safety margin.

\section{APPENDIX \\ Measurement of Methemoglobin, Hemoglobin and Turbidity in Blood Sampled Immediately after Exposure}

Before the exposures to $\mathrm{NF}_{3}$ were begun, it was considered possible that other abnormal blood pigments besides methemoglobin might be produced. Because these pigments might have a short lifetime, it was necessary to employ a method that could be performed quickly and with a minimum of manipulation. Therefore, sampled blood was immediately diluted $1 / 100$ in $\mathrm{M} / 60$ phosphate buffer, $\mathrm{pH} 6.0$, and absorbance curves were recorded from $750 \mathrm{~nm}$ to $400 \mathrm{~nm}$ using a Bausch and Lomb 505 spectrophotometer. Examination of the absorbance curves demonstrated that the only blood pigments present were methemoglobin and oxyhemoglobin (any reduced hemoglobin present had been oxygenated on dilution). The diluted blood solutions were visibly turbid and this turbidity was revealed in the curves as a linear absorbance in the region 690-750 $\mathrm{nm}$ which appeared to affect the combined absorbances of methemoblobin and oxyhemoglobin at lower wavelengths. In order to isolate the effect of the turbidity, difference curves were run by using various combinations of oxyhemoglobin and methemoglobin (produced by adding different concentrations of potassium ferricyanide to 
control blood) in the reference cell of the spectrophotometer and blood from exposed animals in the sample cell. The peaks in the sample curves could be completely smoothed out by the correct combination of oxyhemoglobin and methemoglobin (further evidence of the absence of other blood pigments), and the absorbance due to turbidity increased with decreasing wavelength. At $630 \mathrm{~nm}$, the average absorbance due to turbidity was 1.2 times and at $578 \mathrm{~nm}, 1.3$ times that at $720 \mathrm{~nm}$. At this point it was decided to adapt the procedure to the simultaneous qualitative estimation of turbidity, methemoglobin, and oxyhemoglobin (or total ferrohemoglobin in our system). Since the absorbance at $720 \mathrm{~nm}$ was due only to turbidity, at $630 \mathrm{~nm}$ to turbidity and methemoglobin, and at $578 \mathrm{~nm}$ to turbidity, methemoglobin and oxyhemoglobin, the concentrations of the two pigments and contribution of the turbidity could be estimated by measurement at these 3 wavelengths.

\section{ACKNOWLEDGMENTS}

This research was sponsored by the Aerospace Medical Research Laboratories, Aerospace Medical Division, Air Force Systems Command, Wright-Patterson Air Force Base, Ohio, under Contract F33615-70-C-1046 with SysteMed Corporation.

The technical assistance of Mr. Louis DiPasquale for performance of the exposures of the experimental animals and of Mr. Stanley Erk for development of the analytical method is gratefully acknowledged.

\section{REFERENCES}

Dost, F. N., REED, D. J. AND WANG, C. H. (1970). Toxicology of nitrogen trifluoride. Toxicol. Appl. Pharmacol. 17, 585-596.

FINNEY, D. J. (1964). Probit Analysis, 2nd ed. Cambridge Univ. Press, London and New York.

Haun, C. C., MacEwen, J. D., Vernot, E. H. and Egan, G. F. (1969). The acute inhalation toxicity of monomethyl hydrazine vapor. AMRL-TR-68-169. Aerospace Medical Research Laboratory, Wright-Patterson AFB, Ohio.

HORECKER, B. L. (1945). The occurrence of Heinz bodies in trinitrotoluene workers. J. Ind. Hyg. Toxicol. 27, 85-88.

Hurst, G. L. and Khayat, S. I. (1966). Hydrolysis of nitrogen fluorides. Advan. Chem. 54, 245-260.

JANDL, J. H., ENGLe, L. K. AND Allen, D. W. (1960). Oxidative hemolysis and precipitation of hemoglobin I. Heinz body anemias as an acceleration of red cell aging. J. Clin. Invest. 39, 1818.

Necheles, T. F. And Allen, D. M. (1969). Current concepts, Heinz-body anemias. N. Engl. J. Med. 280, 203-206.

RuFf, O. (1931).Zur Kenntnis derStickstoff-3-Fluorids. Z. Anorg. Allgem. Chem. 197, 273-286.

SELWYN, J. G. (1955). Heinz bodies in red cells after splenectomy and after phenacetin administration. Brit. J. Haematol. 1, 173-183.

SiLVER, S. D. (1946). Constant flow gassing chambers: principles influencing design and operation. J. Lab. Clin. Med. 31, 1153-1161.

Sinha, D. AND Slight, S. D. (1968). Experimental production of Heinz bodies in the pig. Toxicol. Appl. Pharmacol. 12, 435-439.

SPICER, S. S. (1949). Effect of para-aminobenzoic acid on the in vivo oxidation of hemoglobin. J. Ind. Hyg. Toxicol. 31, 204-205.

Torkelson, T. R., Oyen, F., Sadek, S. E. and Rowe, V. K. (1962). Preliminary toxicolngic studies on nitrogen trifluoride. Toxicol. Appl. Pharmacol. 4, 770-781.

von Oettingen, W. F., Neal, P. A., Sievers, R. F., Svirbely, J. L., Monaco, A. P., Horecker, B. L., Yagoda, H., Sweeney, T. R., Peterson, D. C., Alford, W. C., Hauff, V. B. And GAY, H. (1947). Xylidene (C,C-dimethylaniline): its toxicity and potential dangers as compared with those of aniline and an appraisal of the potential hazards from its use in blending gasoline. Nat. Inst. Health Bull. 188. 